\title{
Analysis of risk factors for vitamin B12 deficiency in patients with type 2 diabetes mellitus and its relation to the use of metformin
}

\section{ABSTRACT}

Background. The use of metformin has been associated with vitamin B12 deficiency in patients with type 2 diabetes mellitus.

Objective. The present study evaluates the relationship between vitamin B12 deficiency and its risk factors. Moreover, it investigates the relationship between established deficiency and clinically detectable peripheral neuropathy.

Material and methods. A cross-sectional study involving patients with type 2 diabetes mellitus who were assisted at a public health care service, which is a reference center in Diabetes. Peripheral neuropathy was detected by Neuropathy Symptom Score, Vibration Sensitivity Test, Achilles Reflex and Monofilament Test. Vitamin B12 levels were determined by means of two laboratory measurements.

Results. The study included 316 subjects, from which $\mathbf{9 1 \%}$ were metformin users. Vitamin B12 deficiency was observed in $14 \%$ of participants in the study. All patients with vitamin B12 deficiency used metformin, with an odds ratio of $\mathbf{2 . 6}$ for those using doses higher than $1000 \mathrm{mg} /$ day (95\% confidence interval: 1.3-5.3,

Address for correspondence:

Fabiana Lima Marques

Champagnat avenue, 501, rooms 207 and 208,

Praia da Costa, Espírito Santo, Brazil, zip Code: 29100-010

Phone: $+55 / 27 / 32393666$

Fax: $+55 / 27 / 33251545$

e-mail: fabianalima5@uol.com.br

Clinical Diabetology 2018, 7, 6, 247-252

DOI: $10.5603 /$ DK.2018.0026

Received: 18.09.2018 p = 0.009). Vitamin B12 deficiency was also statistically related to the use of angiotensin-converting enzyme inhibitors $(p=0.02$ ). Peripheral neuropathy was observed in $41 \%$ of patients and was not related to vitamin B12 deficiency. The prevalence of peripheral neuropathy was lower among metformin users $(39 \%$ vs. $60 \% ; p=0.04$ ).

Conclusions. This study demonstrated a dose-dependent association between metformin use and vitamin B12 deficiency, in addition to an association with the use of angiotensin-converting enzyme inhibitors. In contrast, Vitamin B12 deficiency was not related to clinically detected neuropathy. (Clin Diabetol 2018; 7, 6: 247-252)

Key words: diabetes, metformin, vitamin B12, diabetic neuropathy, angiotensin-converting enzyme inhibitors

\section{Introduction}

Metformin is the most widely used oral anti hyperglycemic agent [1]. Most current clinical recommendations suggest that, in the absence of contraindications, metformin should be the first-line medication for the treatment of type 2 diabetes mellitus (T2DM) [2, 3]. Most of the side effects of metformin are mild, transient or clinically difficult to detect, such as B12 deficiency signs [4-9].

The association of vitamin B12 deficiency with the development of megaloblastic anemia has been well established [10-12]. Anemia and macrocytosis can be found, respectively, in $29 \%$ and $36 \%$ of the population 
with cobalamin deficiency [10]. Another consequence of vitamin B12 deficiency is peripheral neuropathy, whose initial manifestations, such as paresthesia and loss of sensitivity to vibration, can be easily confused with the initial presentation of diabetic neuropathy [11-13]. About $50 \%$ of patients with T2DM will develop some degree of diabetic neuropathy throughout their lifetime [14-16]. The clinical suspicion of vitamin B12 deficiency, based on neurological findings, is impaired in this group of patients, leading to a possible underdiagnosis of this important vitamin deficiency. This situation may result in permanent neurological damage if it is not adequately identified and treated [17].

Due to the large number of individuals using metformin, the implementation of a universal screening routine requires higher costs for the public health system. Therefore, the identification of risk factors associated with the development of such deficiency is a way of facilitating the screening of susceptible patients. This is one way to propose a more economical screening system.

The aim of this study was to correlate vitamin B12 deficiency with the use of metformin and to identify other risk factors, such as other medications used by patients with T2DM. A further objective was to investigate the association between peripheral neuropathy and the detection of vitamin B12 deficiency in this group of patients.

\section{Materials and methods}

A cross-sectional study that evaluated patients with T2DM enrolled into the public diabetes health care program in the region of Cariacica, Espírito Santo, Brazil.

\section{Ethical aspects}

The study protocol was approved by the local research ethics committee and all study participants provided a written informed consent.

\section{Selection of the patients}

Patients diagnosed with T2DM, based on the criteria of the American Diabetes Association, were evaluated from November 2015 to July 2016. The exclusion criteria of the study were: vegetarianism, veganism, patients with non-absorptive diseases, chronic endstage renal disease or usage of cobalamin formulations in the previous 6 months.

\section{Data collection}

All selected patients were interviewed by a single physician about how long they had been suffering from diabetes, type of diet, medications used in the previous 6 months (detailed information about the use of met- formin, anti-acids, supplements or any other medications). In detailing the use of metformin, we considered users those who had used that medicine for at least the previous 3 months. They were also questioned by the dosage of metformin. The Neuropathy Symptom Score (NSS) was used to detect neuropathic symptoms $[18,19]$. We used the criteria adopted by the Diagnostic and Statistical Manual of Mental Disorders of the American Psychiatric Association, 5th Edition (DSM-5) for the diagnosis of Alcohol Use Disorder.

The patients underwent a complete physical examination, including examination of both feet. To test the sensitivity to vibration, we used a $128-\mathrm{Hz}$ tuning fork that was positioned on the dorsal side of the hallux and classified the response as normal or decreased [18]. The achilles reflex test was classified as absent, diminished, or normal [18]. Sensitivity to mechanical pressure was tested using the 10-g Semmes-Weinstein monofilament, positioned at four different points on each foot: plantar regions of the hallux and first, third and fifth metatarsals. The detection of any insensitivity point was considered altered [20].

The clinical diagnosis of neuropathy was considered in case of any combination of two of the following findings: neuropathic symptoms, decreased sensitivity (vibration or mechanical pressure) or decreased reflexes of the Achilles tendon [21]. The diagnosis of possible neuropathy was considered in case either one of these findings were detected.

\section{Laboratory evaluation}

Blood samples were collected for measuring of glucose, glycated hemoglobin $\left(\mathrm{HbA}_{1 \mathrm{c}}\right)$, creatinine, lipid profile, iron, ferritin, folic acid, aspartate transaminases, alanine transaminases, thyroid stimulating hormone, free thyroxine and complete blood count. We excluded end-stage renal failure by estimating the glomerular filtration rate using the proposed Modification of Diet in Renal Disease (MDRD) formula. The serum vitamin B12 level was quantified by chemiluminescent assay in the same laboratory and it was repeated on the following day in order to increase the reproducibility of the test. In order to classify vitamin B12 levels, we considered two measurements. As a cut-off, we used values below the reference range (below $211 \mathrm{pg} / \mathrm{mL}$ ), which were considered as B12 deficiency. That value (below $211 \mathrm{pg} / \mathrm{mL}$ ) is the cut-off used in kits by Brazilian laboratories for vitamin B12 dosage, which use the chemiluminescence method; Equipment: Architect; Manufacturer: Abott.

\section{Statistical analyses}

Patients with vitamin B12 deficiency were compared with those without such deficiency as to identify 
possible risk factors, such as metformin use or use of other medications, duration of the T2DM, gender and age. In addition, within the metformin user group, a linear regression analysis was performed in order to correlate the metformin dose with vitamin B12 levels. Finally, vitamin B12 levels were compared between the two groups of patients, with negative and positive neuropathy screening.

The analyses of association between the variables were performed through comparison between groups, correlations and linear regressions. Comparisons between the quantitative variables were analyzed using the Student's $t$ test or the Mann-Whitney test, as appropriate. Categorical variables were analyzed using the chi-square test. The analysis of the association between continuous variables was performed either by means of correlation tests (Pearson or Spearman, as appropriate) or by simple and multiple linear regression tests to estimate the independent influence of the predictor variables in the outcomes. We used following analysis models: univaried, multivaried, linear regression and multiple regression. Regression models were built based on possible risk factors of the sample including the use of medicine. Simple regressions were carried out with all identified variables and, those that showed a correlation at the univaried analysis were reanalyzed through multivaried regression in order to have a possible independent effect assessed.

Sample size was calculated by Epi Info Software based on estimated prevalence of vitamin B12 deficiency in our population, whose sampling power was estimated to be $80 \%$.

All statistical analysis was performed with SigmaStat for Windows (version 3.5, SPSS, Inc., San Rafael, CA). Values of $p<0.05$ were considered statistically significant.

\section{Results}

A total of 316 patients with T2DM were investigated. From which, $91 \%$ were using metformin for an average period of time of 9.8 years. The general characteristics of the group, including the profile of the medications in use, are presented in Table 1.

On average, the group had good metabolic control, with a mean $\mathrm{HbA}_{1 \mathrm{c}}$ level of $7.3 \pm 1.3 \%$, mean $\mathrm{HDL}$ cholesterol level of $46 \pm 11 \mathrm{mg} / \mathrm{dL}$, mean LDL cholesterol level of $86 \pm 30 \mathrm{mg} / \mathrm{dL}$, and mean triglyceride level of $137 \pm 70 \mathrm{mg} / \mathrm{dL}$.

Vitamin B12 deficiency was observed in 14\% of patients with high reproducibility, as shown at Figure 1. Statistical analysis of the group showed that all individuals with vitamin B12 deficiency were using metformin. The risk of vitamin B12 deficiency was sig-
Table 1. General characteristics of the studied group

\begin{tabular}{lc}
\hline General data & \\
Sex F : M* & $237(75): 79(25)$ \\
Age (years)** & $63.8(9.2)$ \\
Duration of T2DM diagnosis (years)*** & $10(5-15)$ \\
Body mass index [kg/m²]** & $30(26-33)$ \\
Smoking* & $20(6 \%)$ \\
Alcohol use* & $8(3 \%)$ \\
Medications in use & \\
Metformin* & $286(91)$ \\
$\quad$ Duration of metformin use (years)*** & $9.8(6.0-13.0)$ \\
$\quad$ Metformin dose [mg]*** & $2000(1500-2550)$ \\
Statin* & $236(75)$ \\
Insulin* & $142(45)$ \\
Angiotensin II receptor blockers* & $121(39)$ \\
Angiotensin-converting & $120(38)$ \\
enzyme inhibitors* & \\
Aspirin* & $115(37)$ \\
Sulfonylurea* & $94(30)$ \\
Proton pump inhibitor* & $76(24)$ \\
Calcium channel antagonist* & $57(18)$ \\
Calcium supplements* & $18(6)$ \\
Other oral anti hyperglycemic agents* & $14(4)$ \\
Histamin antagonist* & $5(2)$ \\
\hline * &
\end{tabular}

${ }^{*} \mathrm{n}(/ \%) ;{ }^{* *}$ mean (SD); ${ }^{* * *}$ median (interquartile range); $\mathrm{F}$ - female; $\mathrm{M}$ - male; T2DM - type 2 diabetes mellitus

nificantly higher in those who used doses greater than $1000 \mathrm{mg}$ /day of metformin (odds ratio [OR] 2.6, 95\% Cl 1.3-5.3, $\mathrm{p}=0.009$ ) (Table 2). Furthermore, in the multiple linear regression models, there was a direct and independent linear association between vitamin B12 levels and metformin dose with statistical significance $(p=0.001$ ) (Table 3 ). Vitamin B12 deficiency was also associated with a significantly higher prevalence of sulfonylurea use, as well as the use of angiotensinconverting enzyme inhibitors (ACEI). In contrast there was no association between vitamin B12 deficiency and time of metformin use $(p=0.102)$ or use of other medications (Table 2).

Multiple regression analyzes confirmed an independent association between vitamin B12 deficiency and metformin use at doses higher than $1000 \mathrm{mg} /$ day $(p=0.019)$ as well as with the use of ACEI $(p=0.02)$, and no correlation was found with other medications (Table 4).

We observed that the Neuropathy Symptom Score (NSS) was positive in $39 \%$ of all patients tested. There was no significant association between the vitamin B12 deficiency and the detection of neuropathy by any of the methods used (Table 2). 


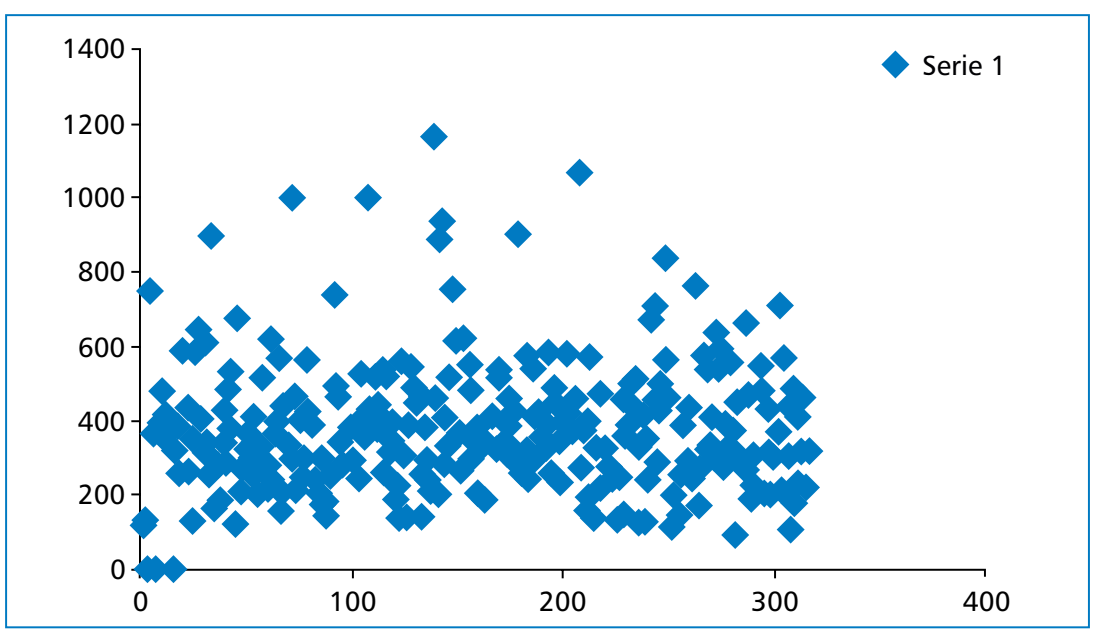

Figure 1. Distribution of B12 levels in the sample. Vitamin B12 levels $\times$ numbers of patients tested

Table 2. Comparison of studied groups with and without vitamin B12 deficiency

\begin{tabular}{|c|c|c|c|}
\hline & With deficiency & Without deficiency & $\mathbf{p}$ \\
\hline N & 43 & 270 & \\
\hline Age (years)* & $64.2(10.7)$ & $63.7(9.0)$ & 0.720 \\
\hline $\operatorname{Sex}(F)$ & $77 \%$ & $75 \%$ & 0.920 \\
\hline Duration of T2DM (years) ${ }^{* *}$ & $10(8-16)$ & $10(5-14)$ & 0.170 \\
\hline $\mathrm{HbA}_{1 \mathrm{c}}(\%)^{* *}$ & $6.8(6.3-7.8)$ & $7.1(6.3-8.1)$ & 0.340 \\
\hline Folic acid $[\mathrm{ng} / \mathrm{mL}]^{* *}$ & $11.4(7.9-14.0)$ & $10.5(7.9-13.2)$ & 0.650 \\
\hline \multicolumn{4}{|l|}{ Metformin use } \\
\hline Percentage of metformin & $100 \%$ & $89 \%$ & 0.040 \\
\hline Duration of use (years) ${ }^{* *}$ & $10.8(7.9-13.8)$ & $9.3(5.8-12.9)$ & 0.102 \\
\hline Dose $[\mathrm{mg}]^{* *}$ & $2550(1700-2550)$ & $2000(1500-2550)$ & 0.016 \\
\hline Use of doses > $1000 \mathrm{mg} /$ day & $37 \%$ & $22 \%$ & 0.009 \\
\hline \multicolumn{4}{|l|}{ Others medications in use } \\
\hline ACEI & $56 \%$ & $35 \%$ & 0.016 \\
\hline Sulfonylurea & $44 \%$ & $27 \%$ & 0.040 \\
\hline PPI & $19 \%$ & $24 \%$ & 0.510 \\
\hline Calcium supplements & 0 & $6 \%$ & 0.168 \\
\hline \multicolumn{4}{|l|}{ Neuropathy } \\
\hline Clinically probable neuropathy & $35 \%$ & $42 \%$ & 0.490 \\
\hline
\end{tabular}

*Mean (standard deviation); ${ }^{*}$ median (interquartile distance); $\mathrm{F}$ - female; T2DM — type 2 diabetes mellitus; HbA $1 \mathrm{c}-\mathrm{glycated}_{\mathrm{f}}$ hemoglobin; $\mathrm{ACEI}$ - angiotensin-converting enzyme inhibitor; PPI — proton pump inhibitor

Table 3. Multiple linear regression models - metformin dose $\times$ vitamin B12 levels

\begin{tabular}{lcccc}
\hline Models & Coefficient & $\begin{array}{c}\text { Standart } \\
\text { error }\end{array}$ & $\mathbf{t}$ & $\mathbf{p}$ \\
\hline Constant & 344.198 & 116.115 & 2.964 & 0.003 \\
Metformin & -0.0485 & 0.0146 & -3.31 & 0.001 \\
dose & & & & \\
\hline
\end{tabular}

\section{Discussion}

In this group of patients with long-term T2DM and good metabolic control, we observed a prevalence of $14 \%$ of vitamin B12 deficiency exclusively among metformin users. Previous studies have shown a prevalence of vitamin B12 deficiency of $10-30 \%$ among users of metformin and 4-7\% among non-metformin users $[5-7,9]$. The high prevalence of patients using met- 
Table 4. Other regression models

\begin{tabular}{lccc}
\hline Models & Coefficient & Standart error & Wald Statistic \\
\hline Constant & -2.664 & 0.298 & 80.131 \\
Metformin $>1000 \mathrm{mg}$ & 0.852 & 0.362 & 5.531 \\
ACEI & 0.788 & 0.339 & 5.404 \\
\hline
\end{tabular}

ACEI - angiotensin-converting enzyme inhibitor

formin has come to our attention. This medication is the first choice drug for treating diabetes and it has been used in large scale. This might have limited the power of analysis on the impact of metformin consumption.

The association between metformin use and vitamin B12 deficiency has recently been confirmed in two meta-analyzes [22, 23], one involving 8.089 patients, which demonstrated that treatment with metformin use is associated with average reduction of $66 \mathrm{pmol} / \mathrm{L}$ in vitamin B12 concentrations. This contributes to a 2.4-fold higher risk of vitamin B12 deficiency among users of this medication [22].

In the present study, the relationship between the use of metformin and the occurrence of vitamin B12 deficiency demonstrated a clear dose-dependence relationship but no association related to duration of metformin use was found. In our study, we concluded that doses higher than $1000 \mathrm{mg}$ have shown independent association with the vitamin B12 deficiency.

In a case-control study [24], the most important risk factor for vitamin B12 deficiency was the use of high doses of metformin, which for each 1 gram increase in metformin dose contributed to a 2-fold increase in the risk of this vitamin deficiency. Although the duration of metformin use has also been indicated as a risk factor for vitamin B12 deficiency in some studies [7, 24], such association was not observed in this analysis. One reason why we could not find any relationship between the duration of metformin use and vitamin B12 deficiency might be related to the fact that patients had been using metformin for an average period of 4.6 years, the time duration the liver might be running out of its reserve of this vitamin.

Among other medications in use, there was an independent association between the use of ACEI and vitamin B12 deficiency. This association has not been demonstrated by any other study published so far. This result demonstrated the difficulty of detecting an independent metabolic effect for metformin in samples from patients using a wide variety of medications. We could propose a possible mechanism that would trigger such occurrence as a factor that determines the alteration of absorptive mechanisms of vitamin in patients using multiples drugs such as ACEI.
In our analysis, we found that $41 \%$ of patients had a clinically detectable peripheral neuropathy, which was established by any combination of two of the following findings: neuropathic symptoms, alteration in sensibility (vibratory or mechanical pressure) and alteration of achilles reflex, $29 \%$ of patients did not show any symptoms of clinical signs tested for neuropathy and $30 \%$ showed only one criterion, which makes diagnosis of neuropathy questionable. Despite high incidence of neuropathy in our population, we found this complication to be significantly lower among metformin users.

Regarding clinical screening for peripheral neuropathy, it is noteworthy that, similar to other studies [25-27], there was no significant association between vitamin B12 deficiency and clinical neuropathy. Although there was a clear association between the use of metformin and the vitamin B12 deficiency, our findings did not demonstrate clinical impact in the main consequence of this deficiency. Several authors have been able to demonstrate a decrease in the serum concentrations of cobalamin among metformin users, but neither one of them could find clinical neuropathic consequences of this vitamin deficiency $[9,25,28,29]$.

\section{Conclusions}

In conclusion, this study reinforces the direct association between the use of increasing doses of metformin and the deficiency of vitamin B12, also suggesting an association between this micronutrient deficit with the use of ACEI. In contrast, our findings minimize the hypothesis that vitamin B12 deficiency is associated with a significant increase in the prevalence of clinically detectable neuropathy in individuals with T2DM. Further studies are needed to provide a better understanding of the effects of metformin on vitamin B12 metabolism, as well as to verify the clinical importance of these findings. This is important to predict and propose better low-cost screening tests for all patients withT2DM using metformin.

\section{Acknowledgements}

None of the authors have any conflict of interest. The study is in compliance with current Brazilian law. 


\section{Institutional approval}

The project was approved by the research ethics committee at the Vila Velha University, linked to the Plataforma Brasil (Brazil Platform), with the number 1.328.545.

\section{REFERENCES}

1. Mazokopakis EE, Starakis IK. Recommendations for diagnosis and management of metformin-induced vitamin B12 (Cbl) deficiency. Diabetes Res Clin Pract. 2012; 97(3): 359-367, doi: 10.1016/j. diabres.2012.06.001, indexed in Pubmed: 22770998.

2. American Diabetes Association. Standards of medical care in diabetes - 2013. Diabetes Care. 2013; 36(Suppl 1): S11-S66, doi: 10.2337/dc13-S011, indexed in Pubmed: 23264422.

3. Nathan DM, Buse JB, Davidson MB, et al. American Diabetes Association, European Association for Study of Diabetes. Medical management of hyperglycemia in type 2 diabetes: a consensus algorithm for the initiation and adjustment of therapy: a consensus statement of the American Diabetes Association and the European Association for the Study of Diabetes. Diabetes Care. 2009; 32(1): 193-203, doi: 10.2337/dc08-9025, indexed in Pubmed: 18945920.

4. Nathan DM, Buse JB, Davidson MB, et al.; Professional Practice Committee, American Diabetes Association; European Association for the Study of Diabetes. Management of hyperglycaemia in type 2 diabetes: a consensus algorithm for the initiation and adjustment of therapy: a consensus statement from the American Diabetes Association and the European Association for the Study of Diabetes. Diabetologia 2006; 49: 1711-1721, doi: 10.2337/dc06-9912.

5. Tomkin GH, Hadden DR, Weaver JA, et al. Vitamin-B12 status of patients on long-term metformin therapy. Br Med J. 1971; 2(5763): 685-687, doi: 10.1136/bmj.2.5763.685, indexed in Pubmed: 5556053.

6. Pflipsen MC, Oh RC, Saguil A, et al. The prevalence of vitamin $\mathrm{B}(12)$ deficiency in patients with type 2 diabetes: a cross-sectional study. J Am Board Fam Med. 2009; 22(5): 528-534, doi: 10.3122/ jabfm.2009.05.090044, indexed in Pubmed: 19734399.

7. Ko SH, Ahn YB, Song KH, et al. Association of vitamin B12 deficiency and metformin use in patients with type 2 diabetes. J Korean Med Sci. 2014; 29(7): 965-972, doi: 10.3346/jkms.2014.29.7.965, indexed in Pubmed: 25045229.

8. Niafar M, Hai F, Porhomayon J, et al. The role of metformin on vitamin B12 deficiency: a meta-analysis review. Intern Emerg Med. 2015; 10(1): 93-102, doi: 10.1007/s11739-014-1157-5, indexed in Pubmed: 25502588.

9. de Jager J, Kooy A, Lehert $P$, et al. Long term treatment with metformin in patients with type 2 diabetes and risk of vitamin B-12 deficiency: randomised placebo controlled trial. BMJ. 2010; 340: c2181, doi: 10.1136/bmj.c2181, indexed in Pubmed: 20488910.

10. Pruthi RK, Tefferi A. Pernicious anemia revisited. Mayo Clin Proc. 1994; 69(2): 144-150, doi: 10.1136/bmj.c2181, indexed in Pubmed: 8309266.

11. Allen RH, Stabler SP, Savage DG, et al. Metabolic abnormalities in cobalamin (vitamin B12) and folate deficiency. FASEB J. 1993; 7(14): 1344-1353, indexed in Pubmed: 7901104.

12. Green R, Kinsella $\amalg$. Current concepts in the diagnosis of cobalamin deficiency. Neurology. 1995; 45(8): 1435-1440, doi: 10.1212/ /wnl.45.8.1435, indexed in Pubmed: 7644036.

13. Hemmer B, Glocker FX, Schumacher $M$, et al. Subacute combined degeneration: clinical, electrophysiological, and magnetic resonance imaging findings. J Neurol Neurosurg Psychiatry. 1998; 65(6): 822-827, doi: 10.1136/jnnp.65.6.822, indexed in Pubmed: 9854956.
14. Dyck PJ, Kratz KM, Karnes JL, et al. The prevalence by staged severity of various types of diabetic neuropathy, retinopathy, and nephropathy in a population-based cohort: the Rochester Diabetic Neuropathy Study. Neurology. 1993; 43(4): 817-824, doi: 10.1212/wnl.43.4.817, indexed in Pubmed: 8469345.

15. Dyck PJ, Litchy WJ, Lehman KA, et al. Variables influencing neuropathic endpoints: the Rochester Diabetic Neuropathy Study of Healthy Subjects. Neurology. 1995; 45(6): 1115-1121, doi: 10.1212/wnl.45.6.1115, indexed in Pubmed: 7783874.

16. Edwards JL, Vincent AM, Cheng HT, et al. Diabetic neuropathy: mechanisms to management. Pharmacol Ther. 2008; 120(1): 1-34, doi: 10.1016/j.pharmthera.2008.05.005, indexed in Pubmed: 18616962.

17. Bell DS. Nondiabetic neuropathy in a patient with diabetes. Endocr Pract. 1995; 1(6): 393-394, doi: 10.4158/EP.1.6.393, indexed in Pubmed: 15251565.

18. Young MJ, Boulton AJ, MacLeod AF, et al. A multicentre study of the prevalence of diabetic peripheral neuropathy in the United Kingdom hospital clinic population. Diabetologia. 1993; 36(2): 150-154, doi: 10.1007/bf00400697, indexed in Pubmed: 8458529.

19. Moreira R, Castro A, Papelbaum M, et al. Tradução para o português e avaliação da confiabilidade de uma escala para diagnóstico da polineuropatia distal diabética. Arq Bras Endocrinol Metab. 2005; 49(6): 944-950, doi: 10.1590/s0004-27302005000600014.

20. Bakker K, Apelqvist J, Schaper NC, et al. International Working Group on Diabetic Foot Editorial Board. Practical guidelines on the management and prevention of the diabetic foot 2011. Diabetes Metab Res Rev. 2012; 28(Suppl 1): 225-231, doi: 10.1002/ dmrr.2253, indexed in Pubmed: 22271742.

21. Tesfaye S, Boulton AJM, Dyck PJ, et al. Toronto Diabetic Neuropathy Expert Group. Diabetic neuropathies: update on definitions, diagnostic criteria, estimation of severity, and treatments. Diabetes Care. 2010; 33(10): 2285-2293, doi: 10.2337/dc10-1303, indexed in Pubmed: 20876709.

22. Niafar M, Hai F, Porhomayon J, et al. The role of metformin on vitamin B12 deficiency: a meta-analysis review. Intern Emerg Med. 2015; 10(1): 93-102, doi: 10.1007/s11739-014-1157-5, indexed in Pubmed: 25502588.

23. Chapman LE, Darling AL, Brown JE. Association between metformin and vitamin B deficiency in patients with type 2 diabetes: A systematic review and meta-analysis. Diabetes Metab. 2016; 42(5): 316-327, doi: 10.1016/j.diabet.2016.03.008, indexed in Pubmed: 27130885.

24. Ting RZW, Szeto CC, Chan MHM, et al. Risk factors of vitamin $\mathrm{B}(12)$ deficiency in patients receiving metformin. Arch Intern Med. 2006; 166(18): 1975-1979, doi: 10.1001/archinte.166.18.1975, indexed in Pubmed: 17030830.

25. Beulens JWJ, Hart HE, Kuijs $R$, et al. Influence of duration and dose of metformin on cobalamin deficiency in type 2 diabetes patients using metformin. Acta Diabetol. 2015; 52(1): 47-53, doi: 10.1007/s00592-014-0597-8, indexed in Pubmed: 24908579.

26. de Groot-Kamphuis DM, van Dijk PR, Groenier KH, et al. Vitamin B12 deficiency and the lack of its consequences in type 2 diabetes patients using metformin. Neth J Med. 2013; 71(7): 386-390, indexed in Pubmed: 24038568.

27. Dunstan DF, Rees JA, Chen S, et al. An observational study of the effect of metformin on B12 status and peripheral neuropathy. Br J Diabetes Vascular Dis. 2012; 12: 189-193, doi: 10.1016/j. dsx.2017.08.014.

28. Obeid R, Jung J, Falk J, et al. Serum vitamin B12 not reflecting vitamin B12 status in patients with type 2 diabetes. Biochimie. 2013; 95(5): 1056-1061, doi: 10.1016/j.biochi.2012.10.028, indexed in Pubmed: 23168250.

29. Greibe E, Trolle B, Bor MV, et al. Metformin lowers serum cobalamin without changing other markers of cobalamin status: a study on women with polycystic ovary syndrome. Nutrients. 2013; 5(7): 2475-2482, doi: 10.3390/nu5072475, indexed in Pubmed: 23857221. 